\title{
The effect of anti-HLA class I antibodies on the immunological properties of human glomerular endothelial cells and their modification by mTOR inhibition or GCN2 kinase activation
}

\author{
THEODOROS ELEFTHERIADIS $^{1 *}$, GEORGIOS PISSAS ${ }^{1 *}$, MARTA CRESPO $^{2}$, GEORGIOS FILIPPIDIS $^{1}$, \\ NIKOLAOS ANTONIADIS ${ }^{3}$, VASSILIOS LIAKOPOULOS ${ }^{1}$ and IOANNIS STEFANIDIS ${ }^{1}$ \\ ${ }^{1}$ Department of Nephrology, Faculty of Medicine, University of Thessaly, Larissa 41110, Greece; \\ ${ }^{2}$ Nephrology Department, Hospital del Mar, Mar Health Park, Hospital del Mar Medical Research Institute, \\ Barcelona 08003, Spain; ${ }^{3}$ Organ Transplant Unit, Faculty of Medicine, \\ Aristotle University of Thessaloniki, Thessaloniki 54642, Greece
}

Received November 19, 2020; Accepted January 26, 2021

DOI: $10.3892 / \mathrm{mmr} .2021 .11994$

\begin{abstract}
In antibody-mediated rejection (ABMR), the graft endothelium is at the forefront of the kidney transplant against the assault from the recipient's humoral immune system, and is a target of the latter. The present study investigated the effect of antibodies against human leukocyte antigen (HLA) class I (anti-HLAI) on the immunological properties of human glomerular endothelial cells. Additionally, the effect of the mammalian target of rapamycin (mTOR) complex 1 (mTORC1) inhibitor (everolimus), or the general control nonderepressible 2 kinase (GCN2K) activator (halofuginone) on anti-HLAI antibody-mediated alterations was assessed. Cell integrity was examined, an lactate dehydrogenase (LDH) release assay was performed and cleaved caspase-3 levels were determined. Furthermore, cell proliferation was analyzed by performing a bromodeoxyuridine assay and the cellular proteins involved in signal transduction or immune effector mechanisms were assessed via western blotting. IL-8, monocyte chemoattractive protein-1 (MCP-1), von Willebrand factor (vWF) and transforming growth factor-beta 1 (TGF- $\beta 1)$ were assayed via ELISA. The results revealed that anti-HLAI triggered integrin signaling, activated mTOR and GCN2K, preserved cell integrity and promoted cell proliferation. Additionally, by increasing intercellular adhesion molecule 1 (ICAM-1), HLA-DR, IL-8 and MCP-1 levels, anti-HLAI enhanced the
\end{abstract}

Correspondence to: Dr Theodoros Eleftheriadis, Department of Nephrology, Faculty of Medicine, University of Thessaly, Biopolis, Mezourlo Hill, Larissa 41110, Greece

E-mail: teleftheriadis@yahoo.com

${ }^{*}$ Contributed equally

Key words: antibody-mediated rejection, anti-human leukocyte antigen, endothelial cells, mTOR, general control nonderepressible 2 kinase ability of immune cells to interact with endothelial cells thus facilitating graft rejection. Contrarily, by upregulating CD46 and CD59, anti-HLAI rendered the endothelium less vulnerable to complement-mediated injury. Finally, by enhancing vWF and TGF- $\beta 1$, anti-HLAI may render the endothelium prothrombotic and facilitate fibrosis and graft failure, respectively. According to our results, mTORC1 inhibition and GCN2K activation may prove useful pharmaceutical targets, as they prevent cell proliferation and downregulate ICAM-1, IL-8, MCP-1 and TGF- $\beta 1$. mTORC1 inhibition also decreases vWF.

\section{Introduction}

Kidney transplantation is the best therapeutic option for end-stage renal disease. Current available immunosuppressive regimens have significantly improved the short-term graft survival, yet graft survival after the first post-transplant year has not been considerably prolonged. The leading cause of graft loss after the first post-transplant year is antibody-mediated rejection (ABMR), a condition without an available effective treatment $(1,2)$. Thus, delineating the molecular mechanisms involved in ABMR, as well as possible therapeutic maneuvers, is of paramount importance.

ABMR results from the de novo donor-specific antibodies (DSA), which are specific mainly, but not exclusively, against the human leukocyte antigens class I (HLAI) and/or class II (HLAII) of the graft (3). Renal endothelial cells display HLAI on their surface, and upon activation, also upregulate HLAII expression (4). The graft endothelium is at the forefront of the kidney transplant against the assault from the recipient's adaptive humoral immune system and not surprisingly a target of the latter. The effector mechanisms of DSA-mediated graft injury include activation of the classical complement pathway, antibody-dependent natural killer (NK) cell cytotoxicity, monocyte cytotoxicity facilitated by antibody-Fc $\gamma \mathrm{R}$ binding, and not uncommonly T-cells are also implicated, resulting in mixed antibody- and cell-mediated rejection $(5,6)$. In the case of active humoral rejection, which has a worse prognosis 
than acute cellular rejection, the presence of neutrophils is a significant finding in the graft biopsies, and intra-capillary thrombosis is also common $(5,6)$.

The mammalian target of rapamycin (mTOR) complex I (mTORC1) inhibitors rapamycin and everolimus are used as immunosuppressants for kidney transplantation. Studies have shown that these inhibitors may interfere with anti-HLA-induced endothelial cell alterations, modifying the graft to be less vulnerable to antibody-mediated injury (7-9). In a model of heart ABMR, an immunosuppressive regimen containing everolimus proved superior to an immunosuppressive regimen containing mycophenolate (10). mTORC1 is activated when there is a sufficient quantity of nutrients, such as certain amino acids, and trophic factors, promoting protein translation and cell proliferation $(11,12)$.

Another sensor of nutrients is the general control nonderepressible 2 kinase $(\mathrm{GCN} 2 \mathrm{~K})$. In case of shortage of an amino-acid, its specific tRNA remains unloaded. Unloaded tRNA induces a conformation change in GCN2K, which is autophosphorylated and activated. Then, GCN2K phosphorylates the eukaryotic initiator factor $2 \alpha$ (eIF $2 \alpha)$, suppressing the general translational program of the cell and selectively enhancing the translation of proteins for adaptation to stress (13). Although activation of GCN2K suppresses adaptive immunity (14-16), activators of this kinase are not still widely used as immunosuppressants. Halofuginone, a veterinary drug against coccidioidomycosis, which activates GCN2K by inhibiting prolyl-tRNA synthetase, has been approved as an orphan drug for the treatment of scleroderma (17-19). However, the drug has not yet gained proper recognition as a general immunosuppressant.

This study aimed to evaluate the effect of anti-HLAI antibodies on the integrity and immunological relevant parameters in primary human glomerular endothelial cells, and whether mTOR inhibition or GCN2K activation may modify any anti-HLAI-induced alterations.

\section{Materials and methods}

Cell culture conditions. Primary human glomerular endothelial cells were purchased from Sciencell Research Laboratories. The culture medium was Dulbecco's modified Eagle's medium (DMEM) low glucose $(5.55 \mathrm{mM})$ (Thermo Fisher Scientific, Inc.) supplemented with $20 \%$ fetal bovine serum (Sigma-Aldrich; Merck Millipore) and antibiotic-antimycotic solution (Sigma-Aldrich; Merck Millipore). The above primary cells are differentiated, well-characterized passage one glomerular endothelial cells. We expanded them in $75 \mathrm{~cm}^{2}$ flasks, and passage two cells were used for the experiments. The cells were cultured at $37^{\circ} \mathrm{C}$ in a humidified atmosphere with $5 \% \mathrm{CO}_{2}$ and cells were seeded in 6 -well plates $\left(3 \times 10^{5}\right.$ cells per well), 24 -well plates ( $1 \times 10^{5}$ cells per well), or 96 -well plates ( $1 \times 10^{4}$ cells per well).

Cells remained untreated or treated with anti-HLAI antibodies (Ultra-LEAF ${ }^{\text {TM }}$ Purified anti-human HLA-A,B,C Antibody, cat. no 311428, Biolegend) at a concentration of $1 \mu \mathrm{g} / \mathrm{ml}$. Anti-HLAI-treated cells were cultured in the presence or not of $10 \mathrm{ng} / \mathrm{ml}$ of the mTORC1 inhibitor everolimus (Selleck Chemicals) or $20 \mathrm{nM}$ of the GCN2K activator halofuginone (Cayman Chemical) or their combination.
The concentration of $1 \mu \mathrm{g} / \mathrm{ml}$ anti-HLAI was based on the concentration administered in previous studies $(7-9,20)$. However, since some studies also used the concentration of $10 \mu \mathrm{g} / \mathrm{ml}$ (20-22), we performed preliminary experiments to evaluate which concentration affects mTOR and GCN2K. Western blotting detection of phosphorylated activated mTOR and $\mathrm{GCN} 2 \mathrm{~K}$ and their substrates' phosphorylation revealed that both concentrations strongly activate both pathways. Thus, we continued the experiments with a concentration of $1 \mu \mathrm{g} / \mathrm{ml}$. The $10 \mathrm{ng} / \mathrm{ml}$ concentration of everolimus was selected because it falls within this drug's therapeutic levels (23). We also performed preliminary experiments. In brief, glomerular endothelial cells were cultured for $48 \mathrm{~h}$ in 96 -well plates at a number of 10,000 cells per well with or without $10 \mathrm{ng} / \mathrm{ml}$ everolimus. Lactate dehydrogenase (LDH) release assay revealed that the above concentration of everolimus is not toxic for glomerular endothelial cells (Fig. 1A). Finally, since there was no available clinical data for halofuginone, we performed preliminary experiments culturing glomerular endothelial cells for $48 \mathrm{~h}$ in 96-well plates at a number of 10,000 cells per well with or without 5,10 , 20 , or $40 \mathrm{nM}$ halofuginone. LDH release assay showed that the concentration of $20 \mathrm{nM}$ was the higher nontoxic concentration for glomerular endothelial cells (Fig. 1B).

The assessment of cellular proteins involved in the evaluated signal transduction pathways or immunological processes was performed after $12 \mathrm{~h}$ of cell culture. Cytotoxicity of the reagents, cell proliferation, and measurement of certain factors secreted in cell culture supernatants were carried out after $48 \mathrm{~h}$ of culture.

Assessment of cell necrosis and proliferation. For evaluating the cytotoxicity of the reagents and cell proliferation, glomerular endothelial cells were cultured in 96-well plates for $48 \mathrm{~h}$ under the aforementioned conditions. Six independent experiments were performed, each one in triplicates.

The cytotoxicity of the reagents was assessed by evaluating cell necrosis with the LDH release assay (Cytotox Non-Radioactive Cytotoxic Assay kit, Promega Corporation). Cytotoxicity was calculated according to the equation Cytotoxicity $(\%)=(\mathrm{LDH}$ in the supernatant: Total LDH $) \times 100$.

Bromodeoxyuridine (BrdU) labeling and immunoenzymatic detection were used to evaluate cell proliferation (Cell Proliferation ELISA, Roche Diagnostics). The proliferation index was calculated according to the equation Proliferation index $=$ optical density of the treated cells: Optical density of the control cells.

Assessment of cellular proteins of interest. For assessing the level of various cellular proteins, glomerular endothelial cells were cultured in 6-well plates for $12 \mathrm{~h}$ under the aforementioned experimental conditions. Three independent experiments were performed.

Cell proteins were extracted with the T-PER tissue protein extraction reagent (Thermo Fisher Scientific, Inc.) supplemented with protease and phosphatase inhibitors (Sigma-Aldrich; Merck Millipore) and measured with Bradford Assay (Sigma-Aldrich; Merck Millipore). For the western blotting, $10 \mu \mathrm{g}$ from each sample were electrophoresed in sodium dodecyl sulfate (SDS) polyacrylamide (4-12\% Bis-Tris 

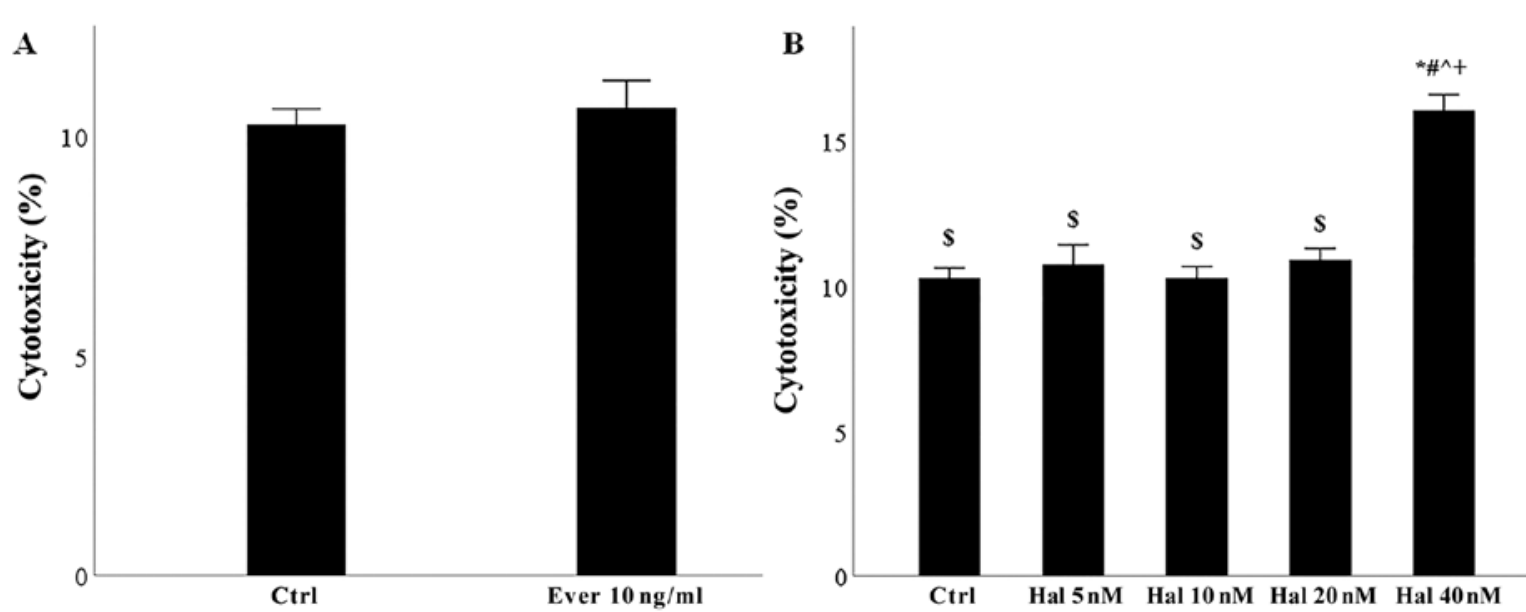

Figure 1. Toxicity of everolimus or halofuginone in glomerular endothelial cells. (A) Everolimus administered at $10 \mathrm{ng} / \mathrm{ml}$ was not toxic. (B) Halofuginone administered at up to $20 \mathrm{nM}$ was not toxic. Data are presented as the mean $\pm \mathrm{SEM}$. ${ }^{*} \mathrm{P}<0.05$ vs. control, ${ }^{\#} \mathrm{P}<0.05$ vs. halofunginone $5 \mathrm{nM},{ }^{\wedge} \mathrm{P}<0.05$ vs. Halofunginone $10 \mathrm{nM},{ }^{+} \mathrm{P}<0.05$ vs. halofumginone $20 \mathrm{nM}$ and ${ }^{\mathrm{S}} \mathrm{P}<0.05$ vs. halofunginone $40 \mathrm{nM}$. HLAI, human leukocyte antigen class I; Hal, halofuginone; Ever, everolimus; Ctrl, control.

gels, Thermo Fisher Scientific, Inc.) and transferred on polyvinylidene fluoride (PVDF) membranes (Thermo Fisher Scientific, Inc.).

Blots were incubated at $4^{\circ} \mathrm{C}$ for $16 \mathrm{~h}$ with the primary antibodies specific against activated cleaved caspase-3 (cleaved caspase-3, 1:1,000, cat. no ab13847, Abcam), focal adhesion kinase (FAK, 1:100, cat. no sc-271126, Santa Cruz Biotechnology, Inc.), phosphorylated at Tyr397 FAK (p-FAK, 1:1,000, cat. no 8556, Cell Signaling Technology, Inc.), mTOR (1:100, cat. no sc-517464, Santa Cruz Biotechnology, Inc.), phosphorylated at Ser2448 mTOR (p-mTOR, 1:100, cat. no sc-293133, Santa Cruz Biotechnology, Inc.), p70S6 kinase (p70S6K, 1:100, cat. no sc-8418, Santa Cruz Biotechnology, Inc.), phosphorylated at Thr389 p70S6K (p-p70S6K, 1:1,000, cat. no 9234, Cell Signaling Technology), protein kinase B (Akt, 1:100, cat. no sc-5298, Santa Cruz Biotechnology, Inc.), phosphorylated at Ser474 Akt (p-Akt, 1:1,000, cat. no 4060, Cell Signaling Technology, Inc.), GCN2 kinase (GCN2K, 1:100, cat. no sc-374609, Santa Cruz Biotechnology, Inc.), phosphorylated at Thr899 GCN2K (p-GCN2K, 1:1,000, cat. no ab75836; Abcam), eIF2 $\alpha$ (1:100, cat. no sc-133132, Cell Signaling Technology, Inc.), phosphorylated at Ser51 eIF2 $\alpha$ (p-eIF2a, 1:1,000, cat. no 9721, Cell Signaling Technology, Inc.), intercellular adhesion molecule 1 (ICAM-1, 1:1,000, cat. no 4915; Cell Signaling Technology), HLA-DR (Ultra-LEAF ${ }^{\mathrm{TM}}$ Purified anti-human HLA-DR Antibody, cat. no 307648, Biolegend), CD46 (1:1,000, cat. no CSB-PA923298, Cusabio), CD59 (1:1,000, cat. no CSB-PA004947YA01HU, Cusabio), and $\beta$-actin (1:5,000, cat no. 4967, Cell Signaling Technology, Inc.). Anti-rabbit IgG, HRP-linked (1:1,000; cat. no. 7074; Cell Signaling Technology, Inc.) or anti-mouse IgG, HRP-linked (1:1,000; cat. no. 7076; Cell Signaling Technology, Inc.) antibodies were used as secondary antibodies and applied for $30 \mathrm{~min}$ at room temperature. The Restore Western Blot Stripping Buffer (Thermo Fisher Scientific, Inc.) was used for reprobing the PVDF blots.

Bands were visualized with the LumiSensor Plus Chemiluminescent HRP substrate kit (GenScript Corporation), and the ImageJ 1.51t software (National Institute of Health) was used for the optical density (OD) measurement of the bands.

Assessment of IL-8, MCP-1, TGF- $\beta 1$, and $v W F$. Interleukin-8 (IL-8), monocyte chemoattractant protein 1 (MCP-1), transforming growth factor-beta 1 (TGF- $\beta 1$ ), and von Willebrand factor (vWF) concentrations were measured in cell culture supernatants of glomerular endothelial cells cultured in 24-well plates for $48 \mathrm{~h}$ under the aforementioned experimental conditions. Six independent experiments were performed.

The measurements were obtained through enzyme-linked immunosorbent assay (ELISA) using the Interleukin-8 Human ELISA kit (Bender Medsystems), the 1/MCAF ELISA kit for MCP-1 (Cusabio), the Human TGF-beta1 ELISA kit (AssayPro), and the Human von Willebrand Factor ELISA kit (Cusabio).

Statistical analysis. Statistical analysis was performed with the IMB SPSS Statistics v.20 (IBM Corp.). For comparison of means, one-way analysis of variance (ANOVA) and Bonferroni's correction test were used. Results were presented as mean \pm standard error of mean (SEM), and statistical significance was set at a $\mathrm{P}<0.05$. Except for the western blotting that evaluated phosphorylated protein $\mathrm{OD}$ to total protein OD ratio, for readers' convenience, all the other western blotting results were depicted after normalization of means for the control group.

\section{Results}

The effect of anti-HLAI antibodies on cell necrosis, apoptosis and proliferation and the impact of halofuginone or everolimus. Neither anti-HLAI antibodies nor their combination with halofuginone or everolimus was cytotoxic. Cytotoxicity was $11.33 \pm 0.11,12.17 \pm 0.38$, $10.67 \pm 0.64,11.50 \pm 0.37$, and $12.17 \pm 0.21 \%$ in control, anti-HLAI-treated cells, anti-HLAI-treated cells with halofuginone, anti-HLAI-treated cells with everolimus, and 

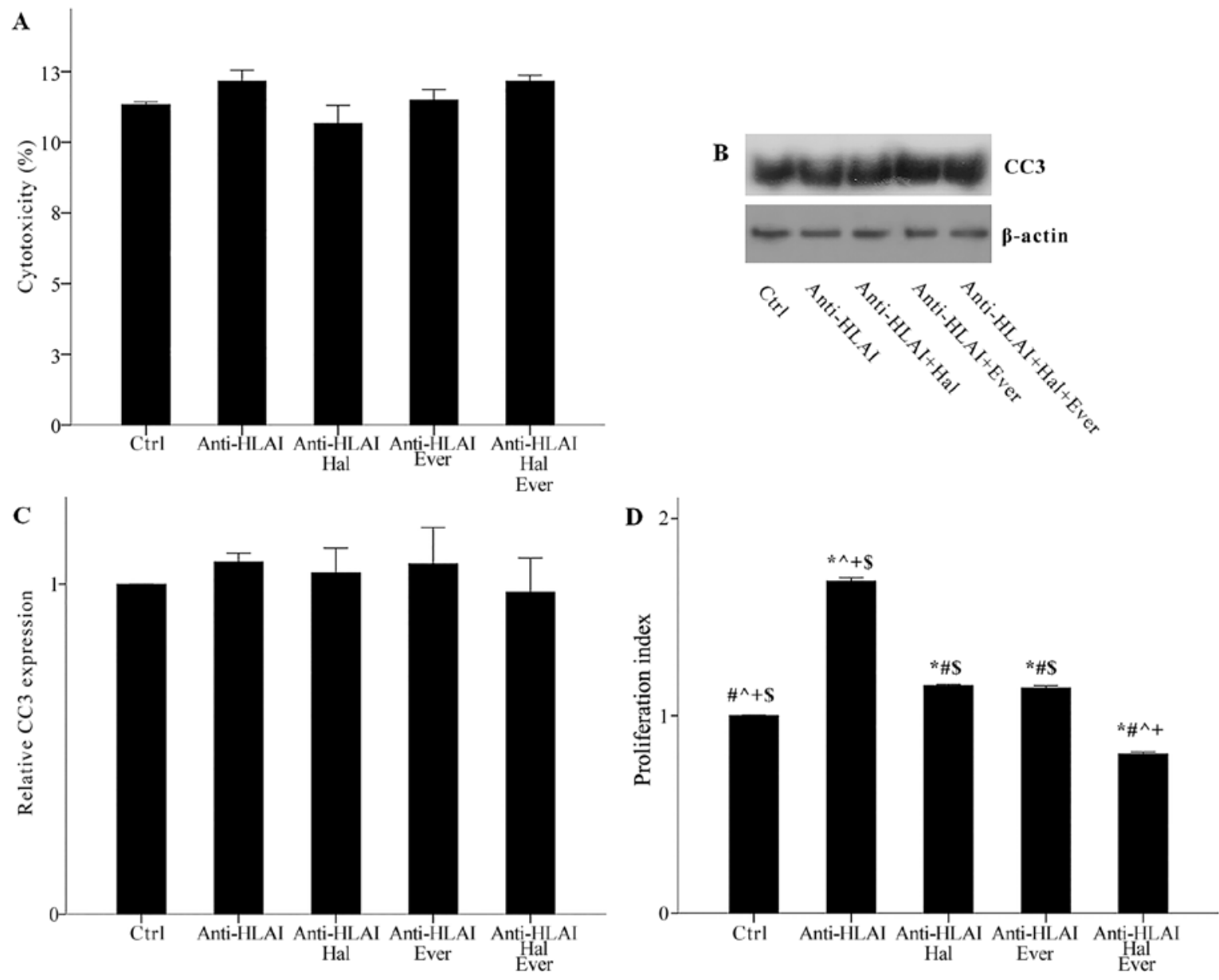

Figure 2. Effect of anti-HLAI on cell necrosis, apoptosis and proliferation, and the impact of halofuginone or everolimus treatment. (A) Neither anti-HLAI antibodies nor their combination with halofuginone or everolimus alone or in combination induced cell necrosis. The same was confirmed for apoptosis assessed by the level of activated cleaved caspase-3. (B) Panel B depicts a representative experiment, while the (C) cumulative results are presented in panel C. (D) Anti-HLAI antibodies promoted cell proliferation, while halofuginone or everolimus inhibited anti-HLAI-induced cell proliferation. Data are presented as the mean \pm SEM. ${ }^{*} \mathrm{P}<0.05$ vs. control cells, ${ }^{\#} \mathrm{P}<0.05$ vs. anti-HLAI-treated cells, ${ }^{\wedge} \mathrm{P}<0.05$ vs. anti-HLAI-treated cells administered halofuginone, ${ }^{+} \mathrm{P}<0.05$ vs. anti-HLAI-treated cells administered everolimus and ${ }^{\$} \mathrm{P}<0.05$ vs. anti-HLAI-treated cells with halofuginone and everolimus. HLAI, human leukocyte antigen class I; Hal, halofuginone; Ever, everolimus; Ctrl, control; CC3, cleaved caspase-3.

anti-HLAI-treated cells with halofuginone and everolimus, respectively (p n.s.) (Fig. 2A).

Neither anti-HLAI antibodies nor their combination with halofuginone or everolimus induced apoptosis, as it was assessed by the level of activated cleaved caspase- 3 . In anti-HLAI-treated cells, anti-HLAI-treated cells with halofuginone, anti-HLAI-treated cells with everolimus, and anti-HLAI-treated cells with halofuginone and everolimus cleaved caspase-3 level was $1.07 \pm 0.03,1.03 \pm 0.07,1.06 \pm 0.11$, and $0.97 \pm 0.10$ fold as found in control cells, respectively (p n.s.) (Fig. 2B and C).

Anti-HLAI antibodies promoted cell proliferation, whereas both halofuginone and everolimus inhibited anti-HLAI-induced cell proliferation. In the anti-HLAI-treated cells proliferation index was $1.68 \pm 0.02$ ( $\mathrm{P}<0.001$, compared to the control). Halofuginone decreased proliferation index to $1.15 \pm 0.01$ $(\mathrm{P}<0.001$, compared to anti-HLAI-treated cells). Everolimus reduced proliferation index to $1.14 \pm 0.01(\mathrm{P}<0.001$, compared to anti-HLAI-treated cells). The combination of halofuginone and everolimus had an even greater effect on anti-HLAI-induced cell proliferation since, in this case, the proliferation index was $0.80 \pm 0.01(\mathrm{P}<0.001$ compared to control cells,
anti-HLAI-treated cells, anti-HLAI-treated cells with halofuginone, and anti-HLAI-treated cells with everolimus (Fig. 2D).

The effect of anti-HLAI antibodies on integrin, $m T O R$, and GCN2K signal transduction and the impact of halofuginone or everolimus. The integrin, mTOR, and GCN2K signal transduction pathways were assessed by the level of phosphorylation of proteins that are phosphorylated once the above pathways are activated. For this purpose, the ratio of phosphorylated to total protein was assessed.

Anti-HLAI antibodies trigger integrin signaling as it was assessed by the p-FAK to total FAK ratio. Compared to the control cells, anti-HLAI antibodies increased p-FAK $(\mathrm{P}<0.001)$. Halofuginone did not affect anti-HLAI-induced FAK phosphorylation ( $\mathrm{p}$ n.s. compared to the anti-HLAI-treated cells). On the contrary, everolimus prevented anti-HLAI-induced FAK phosphorylation (p n.s. compared to the control, and $\mathrm{P}<0.001$ compared to the anti-HLAI-treated cells). The combination of everolimus with halofuginone did not alter the $\mathrm{p}$-FAK level more than everolimus alone ( $\mathrm{p}$ n.s. compared to the control and anti-HLAI-treated cells with everolimus) (Fig. 3A and B). 


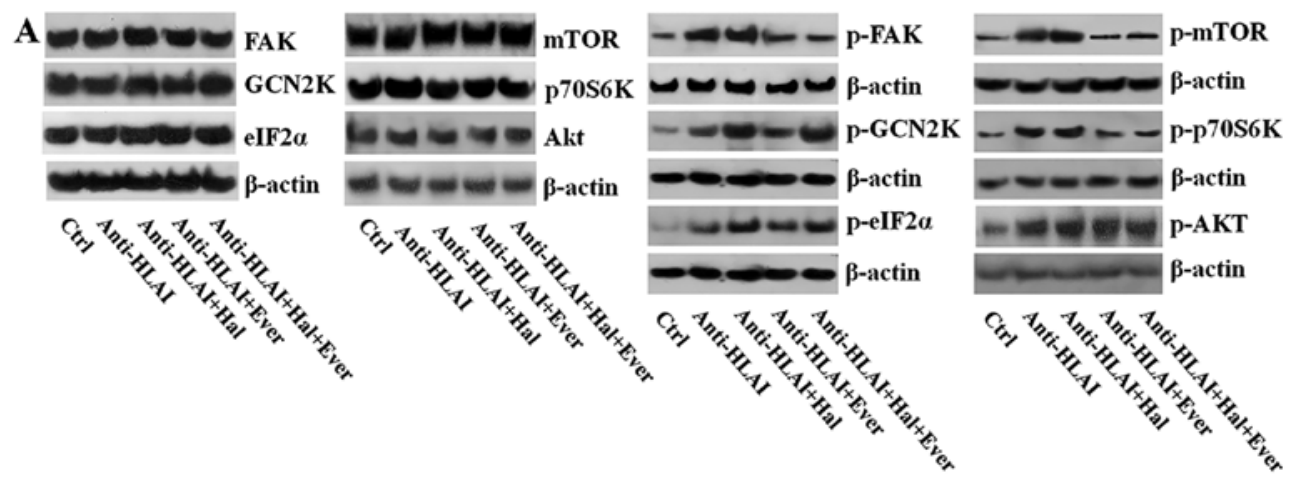

B

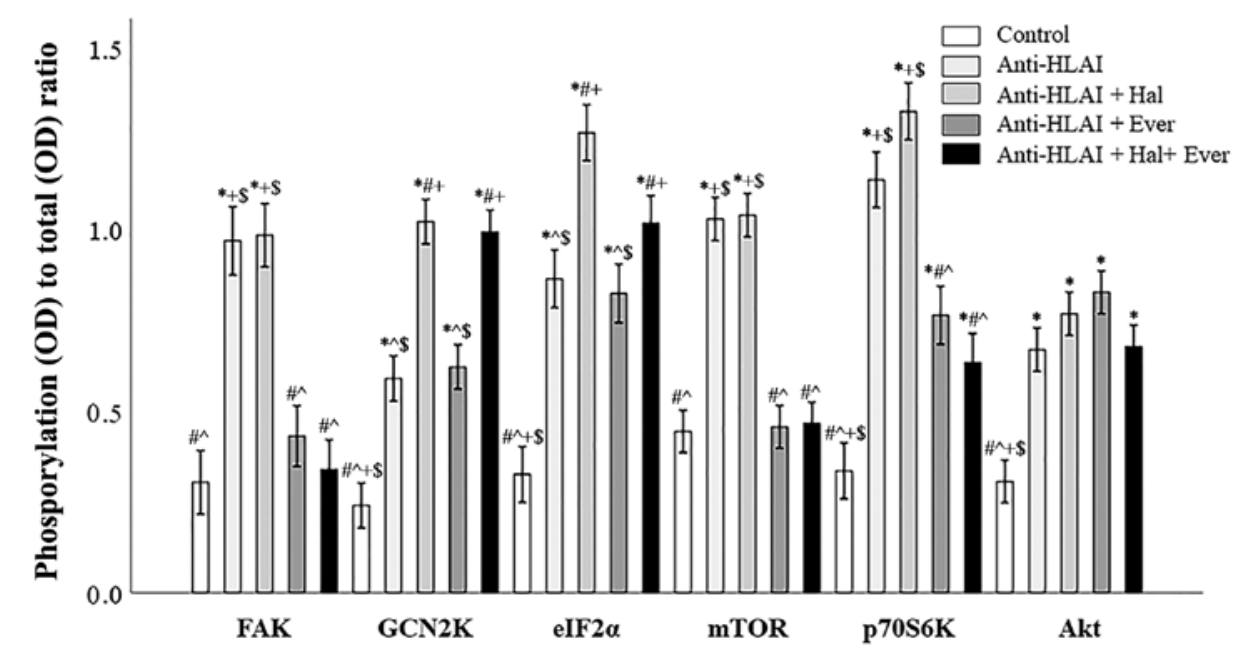

Figure 3. Effect of anti-HLAI on integrins, mTOR and GCN2K signal transduction and the impact of halofuginone or everolimus. (A) Representative experiment for the expression of total and phosphorylated FAK, GCN2K, eIF2 $\alpha$, mTOR, p70S6K and AKT. (B) Cumulative results depict the phosphorylated to total protein ratio and revealed that anti-HLAI antibodies increased p-FAK, p-GCN2K, p-eIF2 $\alpha$, p-mTOR, p-p70S6K and p-AKT levels. Halofuginone increased p-GCN2K and p-eIF2 $\alpha$. Everolimus treatment decreased the anti-HLAI antibody-induced upregulation of p-FAK, p-mTOR and p-p70S6K. Data are presented as the mean \pm SEM. ${ }^{*} \mathrm{P}<0.05$ vs. control cells, ${ }^{\sharp} \mathrm{P}<0.05$ vs. anti-HLAI-treated cells, ${ }^{\wedge} \mathrm{P}<0.05$ vs. anti-HLAI-treated cells administered halofuginone, ${ }^{+} \mathrm{P}<0.05$ vs. anti-HLAI-treated cells administered everolimus and ${ }^{\$} \mathrm{P}<0.05$ vs. anti-HLAI-treated cells with halofuginone and everolimus. HLAI, human leukocyte antigen class I; mTOR, mammalian target of rapamycin; GCN2K, general control nonderepressible 2 kinase; FAK, focal adhesion kinase; eIF2 $\alpha$, eukaryotic initiator factor $2 \alpha$; p, phosphorylated; Hal, halofuginone; Ever, everolimus; Ctrl, control; OD, optical density.

Anti-HLAI antibodies induced GCN2K activation assessed by the ratio of $\mathrm{p}-\mathrm{GCN} 2 \mathrm{~K}$ to total GCN2K ratio. Compared to the control cells, anti-HLAI antibodies increased p-GCN2K $(\mathrm{P}<0.001)$. Halofuginone increased anti-HLAI-induced GCN2K phosphorylation $(\mathrm{P}<0.001$ compared to the anti-HLAI-treated cells). On the contrary, everolimus did not affect anti-HLAI-induced GCN2K phosphorylation ( $\mathrm{P}<0.001$ compared to the control, and $\mathrm{p}$ n.s. compared to the anti-HLAI-treated cells). The combination of halofuginone with everolimus did not alter the p-GCN2K level more than halofuginone alone $(\mathrm{P}<0.001$ compared to the control, and p n.s. compared to anti-HLAI-treated cells, and compared to anti-HLAI-treated cells with halofuginone) (Fig. 3A and B).

The anti-HLAI-induced activation of GCK2K was also confirmed by the ratio of p-eIF2 $\alpha$ to total eIF $2 \alpha$. Compared to the control cells, anti-HLAI antibodies increased p-eIF2 $\alpha$ $(\mathrm{P}<0.001)$. Halofuginone increased anti-HLAI-induced eIF $2 \alpha$ phosphorylation even higher $(\mathrm{P}<0.001$ compared to the anti-HLAI-treated cells). On the contrary, everolimus did not affect anti-HLAI-induced eIF $2 \alpha$ phosphorylation ( $\mathrm{P}<0.001$ compared to the control, and p n.s. compared to the anti-HLAI-treated cells). The combination of halofuginone with everolimus did not alter the p-eIF2 $\alpha$ level more than halofuginone alone $(\mathrm{P}<0.001$ compared to the control, and anti-HLAI-treated cells, and p n.s. compared to anti-HLAI-treated cells with halofuginone) (Fig. 3A and B).

Anti-HLAI antibodies induced mTOR activation assessed by the ratio of p-mTOR to total mTOR. Compared to the control cells, anti-HLAI antibodies increased p-mTOR $(\mathrm{P}<0.001)$. Halofuginone did not affect anti-HLAI-induced mTOR phosphorylation ( $\mathrm{p}$ n.s. compared to the anti-HLAI-treated cells). On the contrary, everolimus prevented anti-HLAI-induced mTOR phosphorylation ( $\mathrm{p}$ n.s. compared to the control, and $\mathrm{P}<0.001$ compared to the anti-HLAI-treated cells). The combination of everolimus with halofuginone did not alter the p-mTOR level more than everolimus alone (p n.s. compared to the control and anti-HLAI-treated cells with everolimus, and $\mathrm{P}<0.001$ compared to anti-HLAI-treated cells) (Fig. 3A and B).

Anti-HLAI-induced mTORC1 activation was also confirmed by the p-p70S6K to total p70S6K ratio. Compared to the control cells, anti-HLAI antibodies increased p-p70S6K $(\mathrm{P}<0.001)$. Halofuginone did not affect anti-HLAI-induced p70S6K phosphorylation (p n.s. compared to the anti-HLAI-treated cells). On the contrary, everolimus reduced anti-HLAI-induced p70S6K phosphorylation ( $\mathrm{P}<0.001$ compared to the control, and $\mathrm{P}<0.001$ compared to 

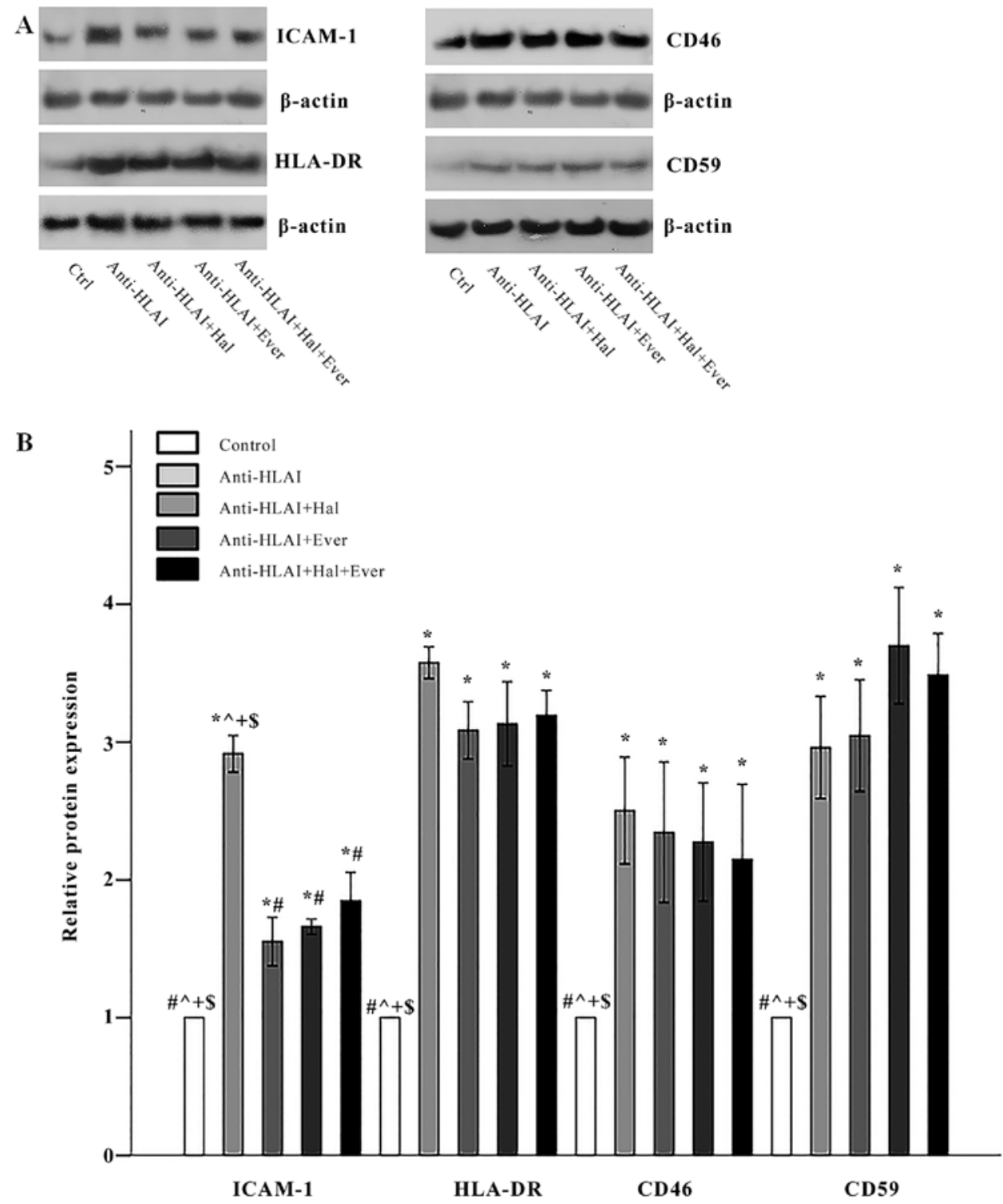

Figure 4. Effect of anti-HLAI on ICAM-1, HLA-DR, CD46 and CD59, and the impact of halofuginone or everolimus treatment. (A) Representative experiment for each of the evaluated factors. (B) Cumulative results are presented. Anti-HLAI antibodies upregulated ICAM-1, HLA-DR, CD46 and CD59. Halofuginone or everolimus treatment decreased ICAM-1. Data are presented as the mean \pm SEM. ${ }^{*} \mathrm{P}<0.05$ vs. control cells, ${ }^{*} \mathrm{P}<0.05$ vs. anti-HLAI-treated cells, ${ }^{\wedge} \mathrm{P}<0.05$ vs. anti-HLAI-treated cells administered halofuginone, ${ }^{+} \mathrm{P}<0.05$ vs. anti-HLAI-treated cells administered everolimus and ${ }^{\$} \mathrm{P}<0.05$ vs. anti-HLAI-treated cells with halofuginone and everolimus. HLAI, human leukocyte antigen class I; ICAM-1, intracellular adhesion molecule-1; Hal, halofuginone; Ever, everolimus; Ctrl, control.

the anti-HLAI-treated cells). The combination of everolimus with halofuginone did not alter the p-p70S6K level more than everolimus alone $(\mathrm{P}<0.001$ compared to the control, $\mathrm{P}<0.001$ compared to anti-HLAI-treated cells and $\mathrm{p}$ n.s. or anti-HLAI-treated cells with everolimus) (Fig. 3A and B).

Anti-HLAI antibodies activated mTORC2 assessed by the p-Akt to total Akt ratio. Compared to the control cells, anti-HLAI antibodies increased p-Akt $(\mathrm{P}<0.001)$. Halofuginone, everolimus, or their combination did not affect anti-HLAI-induced Akt phosphorylation since ( $\mathrm{p}$ n.s compared to anti-HLAI-treated in all cases) (Fig. 3A and B).

The effect of anti-HLAI antibodies on ICAM-1, HLA-DR, CD46, and CD59 and the impact of halofuginone or everolimus. Anti-HLAI antibodies upregulated the expression of ICAM-1 to $2.91 \pm 0.13$ times the control $(\mathrm{P}<0.001)$. Both halofuginone and everolimus, as well as their combination, inhibited
anti-HLAI-induced ICAM-1 overexpression equally. The ICAM-1 level was $1.55 \pm 0.18,1.66 \pm 0.05$, and $1.85 \pm 0.21$ times the control in anti-HLAI-treated cells with halofuginone, anti-HLAI-treated cells with everolimus, and anti-HLAI-treated cells with halofuginone and everolimus, respectively $(\mathrm{P}<0.001$ compared to the control cells and also $\mathrm{P}<0.001$ compared to anti-HLAI-treated cells in all cases) (Fig. 4A and B).

Anti-HLAI antibodies elevated HLA-DR expression to $3.58 \pm 0.11$ times the control $(\mathrm{P}<0.001)$. Halofuginone, everolimus, or their combination did not affect anti-HLAI-induced upregulation of HLA-DR since the HLA-DR level was $3.08 \pm 0.21,3.13 \pm 0.31$, and $3.19 \pm 0.18$ times the control, respectively $(\mathrm{P}<0.001$ compared to the control cells, and $\mathrm{p}$ n.s. compared to anti-HLAI-treated cells) (Fig. 4A and B).

Anti-HLAI antibodies increased CD46 expression to $2.50 \pm 0.39$ times the control $(\mathrm{P}<0.001)$. Halofuginone, everolimus, or their combination did not alter anti-HLAI-induced 

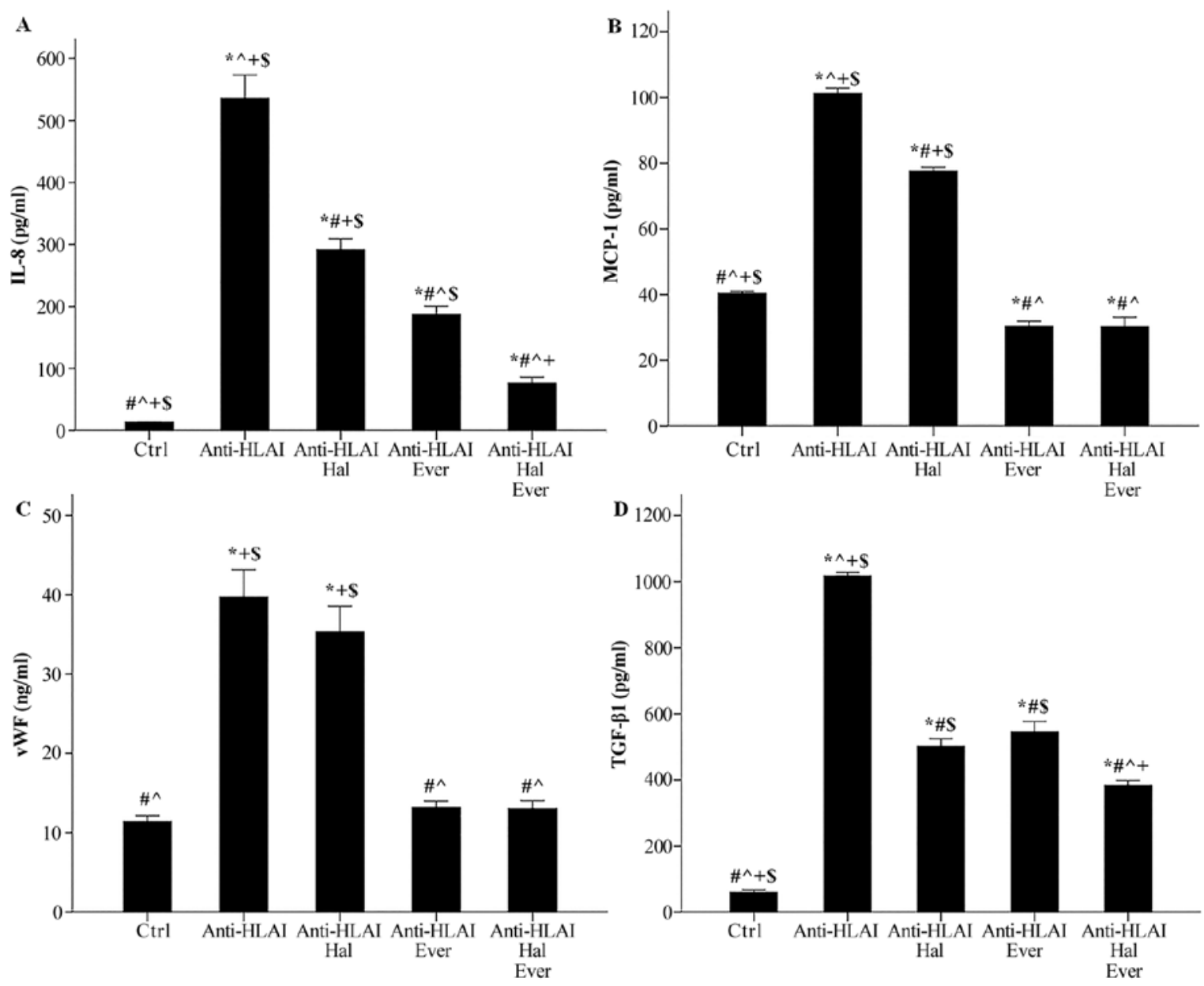

Figure 5. Effect of anti-HLAI on IL-8, MCP-1, vWF and anti-TGF- $\beta 1$, and the impact of halofuginone or everolimus treatment. (A) Anti-HLAI antibodies increased IL-8. Halofuginone or everolimus decreased anti-HLAI-induced IL-8 upregulation. (B) Anti-HLAI antibodies enhanced MCP-1. Halofuginone or everolimus reduced anti-HLAI-induced MCP-1 production. (C) Anti-HLAI antibodies increased vWF. Halofuginone did not affect vWF, while everolimus prevented anti-HLAI-induced vWF upregulation. (D) Anti-HLAI antibodies raised the TGF- $\beta 1$ level. Halofuginone or everolimus suppressed anti-HLAI-induced TGF- $\beta 1$ production. Data are presented as the mean \pm SEM. The superscripts ${ }^{*} \mathrm{P}<0.05$ vs. control cells, ${ }^{\#} \mathrm{P}<0.05$ vs. anti-HLAI-treated cells, ${ }^{\wedge} \mathrm{P}<0.05$ vs anti-HLAI-treated cells administered halofuginone, ${ }^{+} \mathrm{P}<0.05$ vs. anti-HLAI-treated cells administered everolimus and ${ }^{\$} \mathrm{P}<0.05$ vs. anti-HLAI-treated cells with halofuginone and everolimus. HLAI, human leukocyte antigen class I; MCP-1, monocyte chemoattractive protein-1; vWF, von Willebrand factor; Hal, halofuginone; Ever, everolimus; Ctrl, control.

CD46 overexpression since the CD46 level was 2.35 \pm 0.51 , $2.27 \pm 0.43$, and $2.15 \pm 0.55$ times the control, respectively $(\mathrm{P}<0.001$ compared to the control cells, and $\mathrm{p}$ n.s. compared to anti-HLAI-treated cells) (Fig. 4A and B).

Anti-HLAI antibodies enhanced CD59 expression to $2.96 \pm 0.37$ times the control $(\mathrm{P}<0.001)$. Halofuginone, everolimus, or their combination did not change anti-HLAI-induced CD59 overexpression since CD59 level was 3.05 \pm 0.41 , $3.70 \pm 0.42$, and $3.49 \pm 0.30$ times to the control, respectively $(\mathrm{P}<0.001$ compared to the control cells, and $\mathrm{p}$ n.s. compared to anti-HLAI-treated cells) (Fig. 4A and B).

The effect of anti-HLAI antibodies on IL-8, MCP-1, $T G F-\beta 1$, and $v W F$ and the impact of halofuginone or everolimus. Anti-HLAI antibodies raised IL-8 concentration from $13.3 \pm 0.4$ to $536.0 \pm 37.6 \mathrm{pg} / \mathrm{ml}(\mathrm{P}<0.001)$. Halofuginone decreased anti-HLAI-induced IL-8 increase to $291.3 \pm 17.8 \mathrm{pg} / \mathrm{ml}(\mathrm{P}<0.001$ compared to the control, $\mathrm{P}<0.001$ compared to anti-HLAI-treated cells). Everolimus proved a more potent inhibitor of IL-8 production than halofuginone since, in this case, IL- 8 was $187.4 \pm 13.1 \mathrm{pg} / \mathrm{ml}(\mathrm{P}<0.001$ compared to the control, and anti-HLAI-treated cells, and $\mathrm{P}<0.05$ compared to anti-HLAI-treated cells with halofuginone). The combination of halofuginone and everolimus decreased IL-8 concentration further to $76.3 \pm 9.7 \mathrm{pg} / \mathrm{ml}(\mathrm{P}<0.05$ compared to the control and $\mathrm{P}<0.001$ compared to anti-HLAI-treated cells with halofuginone and $\mathrm{P}<0.05$ compared to anti-HLAI-treated cells with everolimus) (Fig. 5A).

Anti-HLAI antibodies enhanced MCP-1 concentration from $40.4 \pm 0.6$ to $101.2 \pm 1.6 \mathrm{pg} / \mathrm{ml}(\mathrm{P}<0.001)$. Halofuginone reduced anti-HLAI-induced $\mathrm{MCP}-1$ augmentation to $77.5 \pm 1.3 \mathrm{pg} / \mathrm{ml}(\mathrm{P}<0.001$ compared to the control, and $\mathrm{P}<0.001$ compared to anti-HLAI-treated cells). Everolimus decreased the MCP-1 level further. In this case, MCP-1 concentration was $30.3 \pm 1.5 \mathrm{pg} / \mathrm{ml}(\mathrm{P}<0.05$ compared to the control, and $\mathrm{P}<0.001$ compared to anti-HLAI-treated cells with halofuginone). The combination of halofuginone and everolimus also decreased MCP-1 concentration to $30.2 \pm 2.9 \mathrm{pg} / \mathrm{ml}$, that is no more than the inhibition induced by everolimus alone $(\mathrm{P}<0.05$ compared to the control, $\mathrm{P}<0.001$ compared to anti-HLAI-treated cells with halofuginone and $\mathrm{p}$ n.s compared to anti-HLAI-treated cells with everolimus) (Fig. 5B). 
Anti-HLAI antibodies increased vWF concentration in the cell culture supernatant from $11.4 \pm 0.7$ to $39.7 \pm 3.5 \mathrm{ng} / \mathrm{ml}$ $(\mathrm{P}<0.001)$. Halofuginone did not affect anti-HLAI-induced vWF production since, in this case, the vWF concentration was $35.3 \pm 3.2 \mathrm{ng} / \mathrm{ml}(\mathrm{P}<0.001$ compared to the control and p n.s. compared to anti-HLAI-treated cells). Everolimus inhibited anti-HLAI-induced vWF enhancement to $13.2 \pm 0.8 \mathrm{ng} / \mathrm{ml}$ ( $\mathrm{p}$ n.s. compared to the control and $\mathrm{P}<0.001$ compared to anti-HLAI-treated cells). The combination of halofuginone and everolimus also reduced vWF concentration, but no more than everolimus alone. In this case, the level of vWF in cell culture supernatants was $13.0 \pm 1.0 \mathrm{ng} / \mathrm{ml}$ (p n.s. compared to the control, $\mathrm{P}<0.001$ compared to anti-HLAI-treated cells, $\mathrm{P}<0.001$ compared to anti-HLAI-treated cells with halofuginone, and $\mathrm{p}$ n.s compared to anti-HLAI-treated cells with everolimus) (Fig. 5C).

Anti-HLAI antibodies upregulated TGF- $\beta 1$ concentration from $59.7 \pm 6.8$ to $1016.3 \pm 11.2 \mathrm{pg} / \mathrm{ml}(\mathrm{P}<0.001)$. Halofuginone reduced anti-HLAI-induced TGF- $\beta 1$ increase to $500.7 \pm 23.9 \mathrm{pg} / \mathrm{ml}(\mathrm{P}<0.001$ compared to the control and $\mathrm{P}<0.001$ compared to anti-HLAI-treated cells). Everolimus decreased the TGF- $\beta 1$ level to the same extent as halofuginone did. In this case, the TGF- $\beta 1$ concentration was $545.0 \pm 31.6 \mathrm{pg} / \mathrm{ml}(\mathrm{P}<0.001$ compared to the control, $\mathrm{P}<0.001$ compared to anti-HLAI-treated cells, and p n.s. compared to anti-HLAI-treated cells with halofuginone). The combination of halofuginone and everolimus also decreased TGF- $\beta 1$ concentration further to $383.0 \pm 15.6 \mathrm{pg} / \mathrm{ml}(\mathrm{P}<0.001$ compared to the control, $\mathrm{P}<0.001$ compared to anti-HLAI-treated cells, $\mathrm{P}<0.05$ compared to anti-HLAI-treated cells with halofuginone, and $\mathrm{P}<0.001$ compared to anti-HLAI-treated cells with everolimus) (Fig. 5D).

\section{Discussion}

Graft endothelial cells are at the forefront of the kidney transplant against the attack from the recipient's immune system. This study evaluated the effect of anti-HLAI antibodies on immunological relevant properties of human glomerular endothelial cells, as well as their modification by mTOR inhibition or GCN2 kinase activation.

First, we examined whether the anti-HLAI antibodies alone or in combination with the mTORC1 inhibitor everolimus or the GCN2K activator halofuginone are cytotoxic or may affect cell proliferation. None of the above reagents induced cell necrosis or cell apoptosis as assessed by LDH release assay or by the level of activated cleaved caspase-3, in which all the apoptotic pathways converge (24), respectively. The aim of our study was not to evaluate the effect of halofuginone or everolimus on resting glomerular endothelial cells, but whether they can modify the anti-HLAI-induced alterations. Thus, any impact of the above substances on unstimulated cells was not assessed. Moreover, no changes in cellular integrity were monitored when these substances were co-administered with anti-HLAI antibodies, allowing us to continue on our experimental approach. In accordance with previous studies, anti-HLAI antibodies induce cell proliferation $(7,8,22,25)$. Everolimus, halofuginone, or their combination prevented anti-HLAI-induced cell proliferation. The latter is expected since activated mTORC1 and inactivated GCN2K promote the necessary for cell proliferation protein synthesis (11-13).
Next, we evaluated whether the above reagents exert the expected signal transduction effects in glomerular endothelial cells. Anti-HLAI antibodies induce integrin clustering and autophosphorylation of FAK at Tyr397. Besides FAK activation, the above phosphorylation turns FAK into a docking site for sarcoma (Src) family kinases, and eventually to mTORC1 activation and cell proliferation $(7,22,25)$. Our experiments confirmed the anti-HLAI-induced FAK phosphorylation. Halofuginone did not affect FAK phosphorylation, while everolimus decreased it significantly, indicating that inhibition of mTORC1 suppresses the anti-HLAI-derived signal transduction at a very early point; and consequently, may have a considerable therapeutic potential. Albeit in different experimental concepts, previous studies also detected that both everolimus and rapamycin downregulate phosphorylation of FAK at Tyr397 (26-28). Upon integrin activation and F-actin polymerization, activated mTOR is recruited to the F-actin polymers and induce further phosphorylation of FAK Tyr residues (29). The latter should be accomplished indirectly through mTOR-mediated Src kinase activation since $\mathrm{mTOR}$ is a serine/threonine and not a tyrosine protein kinase $(11,12)$. Thus, in our experiments, everolimus seems to break a positive feedback loop consisting of anti-HLAI-induced integrin activation, FAK phosphorylation, mTOR activation, and further mTOR-mediated FAK phosphorylation.

Anti-HLAI antibodies induce mTORC1 activation in endothelial cells (7-9). In its turn, activated phosphorylated at Ser2448 mTORC1 phosphorylates other targets such as p70S6K and 4E-BP1, and promotes the necessary for cell proliferation protein synthesis $(11,12)$. In our experiments, anti-HLAI antibodies induced mTORC1 activation assessed by the level of its phosphorylation and by the level of phosphorylation of the mTORC1 target p70S6K. As expected, everolimus prevented anti-HLAI-induced mTORC1 phosphorylation, as well as the phosphorylation of the mTORC1 target p70S6K. On the contrary, halofuginone did not affect the mTORC1 pathway.

According to previous studies, in endothelial cells, besides mTORC1, anti-HLAI antibodies activate mTORC2, too $(7,8)$. Interestingly, although Akt activation is upstream of mTORC1 activation, it is also downstream of mTORC2 activation (12). Activated mTORC2 phosphorylates Akt at Ser473, activating it, and promoting cell survival $(30,31)$. We also found that anti-HLAI antibodies activate mTORC2, assessed by the level of phosphorylated at Ser473 Akt. However, everolimus did not affect the anti-HLAI-induced mTORC2 activation in glomerular endothelial cells. The latter contradicts the results of a previous study, which has shown inhibition of anti-HLAI-induced mTORC2 activation by everolimus (8). This discrepancy may result from different cell types, reagent concentrations, or time-points. Halofuginone did not affect anti-HLAI-induced mTORC2 activation as well.

We evaluated for the first time the effect of anti-HLAI antibodies on GCN2K activation status, and we showed that anti-HLAI antibodies induce GCK2K activation assessed both by the level of its activated phosphorylated at Thr899 form, as well as by the level of phosphorylation of the GCN2K target e-IF2 $\alpha$ at Ser51 (13). We did not evaluate the molecular mechanisms that govern the anti-HLAI-induced GCN2K activation, and the related literature is scarce. Interestingly, one study has shown that perturbation of F-actin dynamics activates GCN2K, and as already noted, integrin clustering induces F-actin 
polymerization (32). Whether such a mechanism is implicated in our model remains to be elucidated. Everolimus did not affect the GCN2K pathway in glomerular endothelial cells.

During ABMR, many immune cells infiltrate and injure the graft. Monocytes, NK-cells, B-cells, and especially in the mixed type of rejection T-cells are present, while in the case of early active humoral rejection, neutrophils may predominate $(5,6)$. ICAM-1 plays a significant role in the interaction between endothelial cells and the aforementioned immune cell types (9,33-38). In accordance with a previous study (21), we found anti-HLAI antibodies to increase ICAM-1 expression in glomerular endothelial cells, a fact that may render the graft more vulnerable to injury from the entire above immune cell types. We also found that mTORC1 inhibition decreases anti-HLAI-induced ICAM-1 upregulation, marking mTORC1 a promising pharmaceutical target for amelioration of humoral rejection. A previous study has shown that mTORC1 inhibitors decrease ICAM-1 signal transduction and the interaction between monocytes and endothelial cells (9). Interestingly, halofuginone also decreased anti-HLAI-induced ICAM-1 overexpression, indicating that the GCN2K pathway may also serve as a therapeutic strategy against humoral rejection.

As noted, especially in the case of mixed cellular and humoral rejection, T-cells play a significant role in graft injury (6). We found that glomerular endothelial cells express the HLAII HLA-DR and that anti-HLAI antibodies enhance the HLA-DR level significantly. The latter has never been evaluated before and indicates that anti-HLAI antibodies may render graft endothelial cells more vulnerable to $\mathrm{CD}^{+}$ T-cell-mediated injury (39). Also, by increasing HLA-DR, anti-HLAI antibodies facilitate anti-HLAII antibodies-mediated injury. Interestingly, in the clinic, kidney graft survival is worse in the presence of late anti-HLAII instead of anti-HLAI DSA (40). Finally, by upregulating HLA-DR, anti-HLAI antibodies may turn glomerular endothelial cells into effective antigen-presenting cells, enhancing both cellular and humoral alloimmune response (39). Unfortunately, neither everolimus nor halofuginone affected anti-HLAI-induced HLA-DR overexpression in glomerular endothelial cells. The latter indicates that anti-HLAI antibodies upregulate HLADR independently of the mTORC1 or the GCN2K pathways.

At first glance, it was surprising that HLA-DR expression was observed in cultured endothelial cells in the absence of interferon (IFN)- $\gamma$ treatment. However, unlike rats and mice, human endothelial cells, especially those that cover the microvasculature, express HLA-DR in vivo constantly (4,41-45). Primary human microvasculature endothelial cells retain HLA-DR expression in culture for several days before losing it unless treated with IFN- $\gamma(4,46)$. We used primary human microvasculature endothelial cells at passage two, i.e., after a short culture period, a fact that explains the observed HLA-DR expression. The molecular mechanisms involved in anti-HLAI-induced HLA-DR upregulation remain to be investigated.

In the clinic, from the various anti-HLA antibodies, the most harmful are those that activate the complement $(47,48)$. For the first time, we evaluated the effect of anti-HLAI antibodies on two membrane complement regulatory proteins, the CD46 and the CD59 (49). We found that anti-HLAI antibodies increase the expression of both CD46 and CD59 in glomerular endothelial cells, possibly creating a negative feedback loop that partially protects the cells from the anti-HLAI-mediated complement activation. Neither everolimus nor halofuginone affected the anti-HLAI-induced upregulation of CD46 and CD59. Thus, neither the mTORC1 nor the GCN2K pathway is responsible for anti-HLAI-induced CD46 and CD59 overexpression in glomerular endothelial cells.

Next, we evaluated the effect of anti-HLAI antibodies on the levels of IL-8 and MCP-1. IL-8 attracts neutrophils (50), whereas MCP-1 attracts monocytes, NK-cells, and T-cells (51). A previous study detected higher IL-8 production by endothelial cells treated with anti-HLAI antibodies (21). Our research confirmed that anti-HLAI antibodies increase IL-8 in glomerular endothelial cells. Everolimus and halofuginone decreased the production of IL-8, with their combination inducing an even greater decrease. Also, we found anti-HLAI antibodies to enhance MCP-1 concentration in the supernatants of glomerular endothelial cells culture. Halofuginone reduced anti-HLAI-induced MCP-1 production, and everolimus exerted the same effect to an even greater extent. Consequently, anti-HLAI antibodies may facilitate the recruitment of immune cells into the graft and rejection. Regarding IL-8 and MCP-1 chemokine production, both mTOR inhibition and GCN2K activation may prove useful therapeutic maneuvers against humoral rejection.

According to many $(20,38)$, but not all researchers (52), anti-HLAI antibodies induce exocytosis of Weibel-Palade bodies in endothelial cells. Weibel-Palade bodies contain the vWF, which, when released, facilitates thrombus formation (53). Interestingly, intra-capillary thrombi are not uncommon in severe active humoral rejection (6). We found anti-HLAI antibodies to increase vWF in the supernatants of glomerular endothelial cell cultures, indicating that anti-HLAI antibodies may render endothelial cell prothrombotic. Between the two tested pharmaceutical compounds, only the mTORC1 inhibitor everolimus prevented the anti-HLAI-induced vWF upregulation.

Similarly to many kidney diseases, the ending remark of chronic graft failure due to ABMR is fibrosis (6). Thus, we evaluated the effect of anti-HLAI antibodies on the production of the archetype profibrotic cytokine TGF- $\beta 1$ (54). Anti-HLAI antibodies significantly increased TGF- $\beta 1$ production by glomerular endothelial cells. Both everolimus and halofuginone reduced TGF- $\beta 1$ and their combination to an even higher degree. Therefore, both mTOR inhibition and GCN2K activation may help in preventing chronic and irreversible fibrosis of the graft.

Our study has many levels of novelty. The effects of anti-HLAI antibodies on human glomerular endothelial was evaluated for the first time. Also, some of the parameters being assessed, such as the effect of anti-HLAI antibodies on HLA-DR, CD46, and CD59, have never been considered before. In addition, our study showed for the first time that the GCN2K activator halofuginone makes the human glomerular endothelium less vulnerable to anti-HLAI-induced injury. Finally, although mTOR inhibitors were introduced in the kidney transplantation immunosuppressive regimen many years ago, they are administered only in a minority of kidney transplant recipients (55). However, recently, the TRANSFORM study showed an immunosuppressive regimen consisting of everolimus, low dose tacrolimus, and prednisone is not inferior to the classic immunosuppressive regimen tacrolimus-mycophenolate-prednisone. Also, the incidence of de novo DSA was lower in the everolimus group, as well as the 
incidence of CMV and BK-virus infection (56). Thus, although mTOR inhibitors are available for many years, there is still significant debate and investigation about their final place in kidney transplantation. Clinical data about the effect of mTOR inhibitors on the glomerular endothelium in the context of ABMR are not available. Our study confirms previous experimental data and evaluates new parameters on the latter topic.

The in vitro nature of our study is a limitation since drawing direct conclusions from in vitro studies to the in vivo model is not always safe. However, under the strictly controlled in vitro conditions, we were able for the first time to detect certain anti-HLAI-induced changes in the immunological properties of human glomerular endothelial cells and the impact of mTOR inhibition or GCN2K activation. Thus, our study could be considered as a starting point for further investigation of the ABMR pathophysiology in vivo, always keeping in mind the interspecies differences.

In conclusion, anti-HLAI antibodies trigger integrin signal transduction, activate mTOR and GCN2K, do not affect cell integrity, and promote cell proliferation. Also, by increasing ICAM-1, HLA-DR, IL-8, and MCP-1, anti-HLAI antibodies enhance the ability of various immune cells to reach and interact with glomerular endothelial cells facilitating graft rejection. On the contrary, by upregulating CD46 and CD59, anti-HLAI antibodies may render glomerular endothelial cells less vulnerable to complement-mediated injury. Finally, by enhancing vWF and TGF- $\beta 1$ production, anti-HLAI antibodies may render endothelium prothrombotic, and facilitate fibrosis and graft failure, respectively. Both mTORC1 inhibition and GCN2K activation may prove useful pharmaceutical targets since they prevent cell proliferation, downregulate ICAM-1, IL-8, MCP-1, and TGF- $\beta 1$ induced by anti-HLAI antibodies. Finally, mTORC1 inhibition decreases vWF.

\section{Acknowledgements}

Not applicable.

\section{Funding}

No funding was received.

\section{Availability of data and materials}

The analyzed datasets used and/or analyzed during the present study are available from the corresponding author on reasonable request.

\section{Authors' contributions}

TE designed the present study. GP and TE performed the experiments. TE, GP, MC, NA, GF and VL analyzed the results. TE and GP wrote the manuscript. IS contributed to the analysis and interpretation of data. TE and GP confirm the authenticity of all raw data. All authors approved the final version of the manuscript.

\section{Ethics approval and consent to participate}

Not applicable.

\section{Patient consent for publication}

Not applicable.

\section{Competing interests}

The authors declare that they have no competing interests

\section{References}

1. Sellares J, de Freitas DG, Mengel M, Reeve J, Einecke G, Sis B, Hidalgo LG, Famulski K, Matas A and Halloran PF: Understanding the causes of kidney transplant failure: The dominant role of antibody-mediated rejection and nonadherence. Am J Transplant 12: 388-399, 2012.

2. Abramowicz D, Oberbauer R, Heemann U, Viklicky O, Peruzzi L, Mariat C, Crespo M, Budde K and Oniscu GC: Recent advances in kidney transplantation: A viewpoint from the descartes advisory board. Nephrol Dial Transplant 33: 1699-1707, 2018.

3. Loupy A and Lefaucheur C: Antibody-mediated rejection of solid-organ allografts. N Engl J Med 379: 1150-1160, 2018.

4. Muczynski KA, Ekle DM, Coder DM and Anderson SK: Normal human kidney HLA-DR-expressing renal microvascular endothelial cells: Characterization, isolation, and regulation of MHC class II expression. J Am Soc Nephrol 14: 1336-1348, 2003.

5. Thomas KA, Valenzuela NM and Reed EF: The perfect storm: HLA antibodies, complement, Fc $\gamma$ Rs, and endothelium in transplant rejection. Trends Mol Med 21: 319-329, 2015.

6. Katsuma A, Yamakawa T, Nakada Y, Yamamoto I and Yokoo T: Histopathological findings in transplanted kidneys. Renal Replacement Therapy 3: 6, 2017.

7. Jindra PT, Jin YP, Rozengurt E and Reed EF: HLA class I antibody-mediated endothelial cell proliferation via the mTOR pathway. J Immunol 180: 2357-2366, 2008.

8. Jin YP, Valenzuela NM, Ziegler ME, Rozengurt E and Reed EF: Everolimus inhibits Anti-HLA I antibody-mediated endothelial cell signaling, migration and proliferation more potently than sirolimus. Am J Transplant 14: 806-819, 2014.

9. Salehi S, Sosa RA, Jin YP, Kageyama S, Fishbein MC, RozengurtE, Kupiec-Weglinski JW and Reed EF: Outside-in HLA class I signaling regulates ICAM-1 clustering and endothelial cell-monocyte interactions via mTOR in transplant antibody-mediated rejection. Am J Transplant 18: 1096-1109, 2018.

10. Li F, Rao P, Hong L, Fishbein MC, Gjertson DW and Reed EF: OR49 effect of everolimus immunotherapy on HLA-antibody mediated activation of endothelial cells in heart transplantation. Hum Immunol 78: 46, 2017.

11. Laplante M and Sabatini DM: mTOR signaling at a glance. J Cell Sci 122: 3589-3594, 2009.

12. Saran U, Foti M and Dufour JF: Cellular and molecular effects of the mTOR inhibitor everolimus. Clin Sci (Lond) 129: 895-914, 2015.

13. Castilho BA, Shanmugam R, Silva RC, Ramesh R, Himme BM and Sattlegger E: Keeping the eIF2 alpha kinase Gcn2 in check. Biochim Biophys Acta 1843: 1948-1968, 2014.

14. Munn DH, Sharma MD, Baban B, Harding HP, Zhang Y, Ron D and Mellor AL: GCN2 kinase in T cells mediates proliferative arrest and anergy induction in response to indoleamine 2,3-dioxygenase. Immunity 22: 633-642, 2005.

15. Eleftheriadis T, Pissas G, Antoniadi G, Spanoulis A, Liakopoulos V and Stefanidis I: Indoleamine 2,3-dioxygenase increases p53 levels in alloreactive human T cells, and both indoleamine 2,3-dioxygenase and p53 suppress glucose uptake, glycolysis and proliferation. Int Immunol 26: 673-684, 2014.

16. Eleftheriadis T, Pissas G, Antoniadi G, Liakopoulos V and Stefanidis I: Indoleamine 2,3-dioxygenase depletes tryptophan, activates general control non-derepressible 2 kinase and down-regulates key enzymes involved in fatty acid synthesis in primary human $\mathrm{CD}^{+}{ }^{+} \mathrm{T}$ cells. Immunology 146: 292-300, 2015.

17. Pines M and Spector I: Halofuginone-the multifaceted molecule. Molecules 20: 573-594, 2015.

18. Sundrud MS, Koralov SB, Feuerer M, Calado DP, Kozhaya AE, Rhule-Smith A, Lefebvre RE, Unutmaz D, Mazitschek R, Waldner $\mathrm{H}$, et al: Halofuginone inhibits TH17 cell differentiation by activating the amino acid starvation response. Science 324 : $1334-1338,2009$. 
19. Carlson TJ, Pellerin A, Djuretic IM, Trivigno C, Koralov SB Rao A and Sundrud MS: Halofuginone-induced amino acid starvation regulates Stat3-dependent Th17 effector function and reduces established autoimmune inflammation. J Immunol 192: 2167-2176, 2014.

20. Yamakuchi M, Kirkiles-Smith NC, Ferlito M, Cameron SJ, Bao C, Fox-Talbot K, Wasowska BA, Baldwin WM III, Pober JS and Lowenstein CJ: Antibody to human leukocyte antigen triggers endothelial exocytosis. Proc Natl Acad Sci USA 104: 1301-1306, 2007.

21. Naemi FM, Carter V, Kirby JA and Ali S: Anti-donor HLA class I antibodies: Pathways to endothelial cell activation and cell-mediated allograft rejection. Transplantation 96: 258-266, 2013.

22. Jin YP, Singh RP, Du ZY, Rajasekaran AK, Rozengurt E and Reed EF: Ligation of HLA class I molecules on endothelial cells induces phosphorylation of Src, paxillin, and focal adhesion kinase in an actin-dependent manner. J Immunol 168: 5415-5423, 2002.

23. Rostaing L, Christiaans MH, Kovarik JM and Pascual J: The pharmacokinetics of everolimus in de novo kidney transplant patients receiving tacrolimus: An analysis from the randomized ASSET study. Ann Transplant 19: 337-345, 2014.

24. Fadeel B and Orrenius S: Apoptosis: A basic biological phenomenon with wide-ranging implications in human disease. J Intern Med 258: 479-517, 2005.

25. Zhang X, Rozengurt E and Reed EF: HLA class I molecules partner with integrin $\beta 4$ to stimulate endothelial cell proliferation and migration. Sci Signal 3: ra85, 2010.

26. Liu L, Chen L, Chung J and Huang S: Rapamycin inhibits F-actin reorganization and phosphorylation of focal adhesion proteins. Oncogene 27: 4998-5010, 2008.

27. Drolet MC, Desbiens-Brassard V, Roussel E, Tu V, Couet J and Arsenault M: Blockade of the acute activation of mTOR complex 1 decreases hypertrophy development in rats with severe aortic valve regurgitation. Springerplus 4: 435, 2015.

28. Jiao Y, Li G, Li Q, Ali R, Qin L, Li W, Qyang Y, Greif DM, Geirsson A, Humphrey JD and Tellides G: mTOR (Mechanistic Target of Rapamycin) inhibition decreases mechanosignaling, collagen accumulation, and stiffening of the thoracic aorta in elastin-deficient mice. Arterioscler Thromb Vasc Biol 37: 1657-1666, 2017

29. Lee FY, Zhen YY, Yuen CM, Fan R, Chen YT, Sheu JJ, Chen YL, Wang CJ, Sun CK and Yip HK: The mTOR-FAK mechanotransduction signaling axis for focal adhesion maturation and cell proliferation. Am J Transl Res 9: 1603-1617, 2017.

30. Sarbassov DD: Phosphorylation and regulation of Akt/PKB by the Rictor-mTOR complex. Science 307: 1098-1101, 2005.

31. Jacinto E, Facchinetti V, Liu D, Soto N, Wei S, Jung SY, Huang Q, Qin J and Su B: SIN1/MIP1 Maintains rictor-mTOR complex integrity and regulates Akt phosphorylation and substrate specificity. Cell 127: 125-137, 2006

32. Silva RC, Sattlegger E and Castilho BA: Perturbations in actin dynamics reconfigure protein complexes that modulate $\mathrm{GCN} 2$ activity and promote an eIF2 response. J Cell Sci 129: 4521-4533, 2016.

33. Yang L, Froio RM, Sciuto TE, Dvorak AM, Alon R and Luscinskas FW: ICAM-1 regulates neutrophil adhesion and transcellular migration of TNF-alpha-activated vascular endothelium under flow. Blood 106: 584-592, 2005.

34. Kaizuka Y, Douglass AD, Varma R, Dustin ML and Vale RD: Mechanisms for segregating $T$ cell receptor and adhesion molecules during immunological synapse formation in Jurkat T cells. Proc Natl Acad Sci USA 104: 20296-20301, 2007.

35. Kuokkanen E, Šuštar V and Mattila PK: Molecular control of B cell activation and immunological synapse formation. Traffic 16 311-326, 2015.

36. Barber DF, Faure M and Long EO: LFA-1 contributes an early signal for NK cell cytotoxicity. J Immunol 173: 3653-3659, 2004

37. Hsu HT and Orange JS: Distinct integrin-dependent signals define requirements for lytic granule convergence and polarization in natural killer cells. Sci Signal 7: pe24, 2014.

38. Valenzuela NM, Mulder A and Reed EF: HLA class I antibodies trigger increased adherence of monocytes to endothelial cells by eliciting an increase in endothelial P-selectin and, depending on subclass, by engaging Fc $\gamma$ Rs. J Immunol 190: 6635-6650, 2013.
39. Neefjes J, Jongsma ML, Paul P and Bakke O: Towards a systems understanding of MHC class I and MHC class II antigen presentation. Nat Rev Immunol 11: 823-836, 2011.

40. Bentall A, Cornell LD, Gloor JM, Park WD, Gandhi MJ, Winters JL, Chedid MF, Dean PG and Stegall MD: Five-year outcomes in living donor kidney transplants with a positive crossmatch. Am J Transplant 13: 76-85, 2013.

41. Mestas J and Hughes CC: Of mice and not men: Differences between mouse and human immunology. J Immunol 172: 2731-2738, 2004

42. Hayry P, von Willebrand E and Andersson LC: Expression of HLA-ABC and -DR locus antigens on human kidney, endothelial, tubular and glomerular cells. Scand J Immunol 11: 303-310, 1980.

43. Evans PR, Trickett LP, Smith JL, MacIver AG, Tate D and Slapak M: Varying expression of major histocompatibility complex antigens on human renal endothelium and epithelium. Br J Exp Pathol 66: 79-87, 1985.

44. Daar AS, Fuggle SV, Fabre JW, Ting A and Morris PJ: The detailed distribution of mhc class II antigens in normal human organs. Transplantation 38: 293-298, 1984.

45. Muczynski KA, Cotner T and Anderson SK: Unusual expression of human lymphocyte antigen class II in normal renal microvascular endothelium. Kidney Int 59: 488-497, 2001.

46. McDouall RM, Yacoub M and Rose ML: Isolation, culture, and characterisation of MHC class II-positive microvascular endothelial cells from the human heart. Microvasc Res 51: 137-152, 1996.

47. Orandi BJ, Alachkar N, Kraus ES, Naqvi F, Lonze BE, Lees L, Van Arendonk KJ, Wickliffe C, Bagnasco SM, Zachary AA, et al: Presentation and outcomes of $\mathrm{C} 4 \mathrm{~d}$-negative antibody-mediated rejection after kidney transplantation. Am J Transplant 16: 213-220, 2015.

48. Loupy A,LefaucheurC, Vernerey D, PruggerC, Duong van Huyen JP, Mooney N, Suberbielle C, Frémeaux-Bacchi V, Méjean A, Desgrandchamps F, et al: Complement-binding anti-HLA antibodies and kidney-allograft survival. N Engl J Med 369: 1215-1226, 2013.

49. Merle NS, Church SE, Fremeaux-Bacchi V and Roumenina LT: Complement System Part I-molecular mechanisms of activation and regulation. Front Immunol 6: 262, 2015.

50. Matsushima K, Baldwin ET and Mukaida N: Interleukin-8 and MCAF: Novel leukocyte recruitment and activating cytokines. Chem Immunol 51: 236-265, 1992.

51. Deshmane SL, Kremlev S, Amini S and Sawaya BE: Monocyte chemoattractant Protein-1 (MCP-1): An overview. J Interferon Cytokine Res 29: 313-326, 2009.

52. Meli A, Carter T, McCormack A, Hannah MJ and Rose ML: Antibody alone is not a stimulator of exocytosis of weibel-palade bodies from human endothelial cells. Transplantation 94 794-801, 2012

53. Hassan MI, Saxena A and Ahmad F: Structure and function of von Willebrand factor. Blood Coagul Fibrinolysis 23: 11-22, 2012.

54. Prud'homme GJ: Pathobiology of transforming growth factor beta in cancer, fibrosis and immunologic disease, and therapeutic considerations. Lab Invest 87: 1077-1091, 2007.

55. Hart A, Smith JM, Skeans MA, Gustafson SK, Stewart DE, Cherikh WS, Wainright JL, Boyle G, Snyder JJ, Kasiske BL and Israni AK: Kidney. Am J Transplant 16 (Suppl 2): S11-S46, 2016.

56. Berger SP, Sommerer C, Witzke O, Tedesco H, Chadban S, Mulgaonkar S, Qazi Y, de Fijter JW, Oppenheimer F, Cruzado JM, et al: Two-year outcomes in de novo renal transplant recipients receiving everolimus-facilitated calcineurin inhibitor reduction regimen from the TRANSFORM study. Am J Transplant 19 3018-3034, 2019.

This work is licensed under a Creative Commons Attribution-NonCommercial-NoDerivatives 4.0 International (CC BY-NC-ND 4.0) License. 